\title{
DESCRIPTION OF THE PUPA OF TOXOPHORA VIRGATA O. S.
}

\author{
BY C. H. TYLER TOWNSEND.
}

The description given below has been drawn from a pupal skin of Toxophora virgata $\mathrm{O}$. S., sent me with the fly for determination by Professor C. P. Gillette, who bred the species at Fort Collins, Colo., from the nest of a wasp belonging to the genus Odynerus. Dr. Fr. Brauer, in his work on dipterous larvae (Denkschr. math.-natur. kais. akad. wissensch. 1883 , bd. xlvii, pp. 27-28), mentions the characters of the pupae of the European Anthrax Alava L. and Bombylius major L., and gives a rather diagrammatic figure of a false pupa of Argyramoeba tripunctata Meig. Dr. T. Algernon Chapman gave a detailed description of the pupa of B. major five years before (Ent. mo. mag. 1878 , v. xiv, pp. 198-200); it has been figured by Imhoff (Isis, I834), and later by Westwood (Intr. class. ins. v. ii, p. 538). Dr. C. V. Riley has described and figured the pupae of Systoechus oreas $\mathrm{O}$. S. and Triodites mus O. S. (Rep. U. S. ent. comm. ii, pp. 267-269). These, if I am not mistaken, are about the only genera the pupae of which have been described. The following description will therefore be of interest as furnishing the first definition of the pupal characters in the genus Toxophora, and also as showing the very material differences in pupal structure between this genus and those that have been previously studied.
It will be noticed that the pupal segment which Dr. Brauer calls the first abdominal, I have termed the scutellar. I used the term merely as a matter of convenience, and before referring to Dr. Brauer's work. It, however, seems preferable to designate this segment by some other name than that used by Brauer, since it does not pertain to any part of the abdomen of the perfect insect, but, dorsally, encloses the scutellum which belongs to the mesothorax. I have therefore adhered to the term scutellar segment, and designate the segments which follow as the ist to the 8th abdominal, the 8th being also called the anal.

Dr. Chapman must have been in error when he stated (1. c. 200) that no parts of the perfect fly were formed in the cephalic horns. It is very apparent that the first antennal joint of Toxophora is encased in the upper pair of horns described below, the second joint being reflexed beneath it, and the peculiar awl-shaped third joint being encased in the spine-shaped posterior process of the lower pair of horns. The upper pair is hollow except the tips, and divided longitudinally by a chitinous septum.

Pupa of Toxophora virgata O. S.- Whitish, with more or less of a flavous tinge, especially the sternal portions and wing and leg sheaths; cephalic horns rufous brown, tips nearly black; proboscideal sheath 
concolorous with sternum; anal hooks rufous brown; long lateral filamentous hairs of abdominal segments rufous, the scattered hairs in the dorsal rows of spines and on sides of venter pale rufous; dorsal rows of appressed spines rufous, darker on tips of spines; spiracles brownish. Four cephalic horns; the upper pair (antennal cases) soldered together on fully their basal twothirds, much longer and larger than the lower pair, straight and not hooked, stout at base, corrugated and roughened basally but smooth and polished on terminal portion; the lower pair is very short, widely separated, and springs one on each side from the outer base of the upper pair, being continued posteriorly in a spine-shaped process (sheath of third antennal joint); each horn of the upper pair bears immediately outside its dorsal edge at base a hair arising from an ocellus-like impression, and a similar hair on the outer side less than half way to tip arising from a slight depression of the surface; each horn of the lower pair has a hair arising from the integument just below and inside its base. Sheath of proboscis closely appressed to the sternum, and extending back to a point immediately below base of scutellar segment. Cephalic segment moulded above to the shape of the eyes of the imago, constricted posteriorly at its junction with the thorax, with a short hair on each side at the posterior margin laterally and a little inferiorly. Thorax (the soldered proscutum and mesoscutum minus the scutellum) but little wider than head, constricted anteriorly, bulging laterally behind at wing bases; dorso-pleural region with three weak hairs arranged in a triangle and considerably removed from each other, the upper and lower ones in a perpendicular line and the third posterior to this line and about equally distant from the other two; leg and wing sheaths free, extending under the abdomen, the two posterior leg sheaths extending fully to base of fifth abdominal segment (6th abdominal segment of Brauer), the wing sheaths nearly to middle of second abdominal segment; scutellar segment with six or seven lateral hairs anteriorly. Abdominal segments I to 4 of nearly the same width (the 4 th but slightly narrower), and a little wider than scutellar segment; segments 5 to 7 successively narrower, the $7^{\text {th }}$ fully one third the width of basal segments; segments I to 7 armed on the dorsum with a median transverse row of closely set perfectly appressed posteriorly directed spines, those in the middle of the rows being a little shorter than those on the sides, each row (except the one on the $7^{\text {th }}$ segment) approximated at its ends to the anterior margin and in its middle to the posterior margin of the segment; these rows of appressed spines are in addition sparsely set with posteriorly directed appressed hairs two or three times the length of the spines, the hairs being longest on the sides; the lateral hairs on scutellar segment and those among the rows of spines on the abdominal segments are microscopically pubescent. Scutellar segment and abdominal segments $\mathrm{I}$ to 6 furnished on their inferior lateral edge each with three (except 6th segment which has only two) long inferiorly and a little outwardly directed filamentous or thread-like hairs on each side, those on the scutellar segment usually directed straight outward (instead of inferiorly) and curved suddenly forward; these hairs are nearly all much longer than the width of the segments from which they depend, except those on the 6th abdominal segment which are about as long as the width of the segment; those on the first two basal segments are considerably the longest; a few shorter hairs spring from the lateral ventral surfaces of segments $\mathrm{I}$ to 6 ; the last are microscopically pubescent, but the long filamentous hairs are only sparsely so on their distal portions. Seventh segment with posteriorly directed appressed hairs on sides, but without hairs or only short weak ones on ventral surface. Anal segment a little more narrowed than $7^{\text {th }}$, directed somewhat downward as is also the 7 th, less dis- 
tinctly separated from the seventh than are the other segments from each other, without hairs, but armed with two pairs of terminal hooks; the upper or anterior pair blunt spine-like, approximated and stout at base, somewhat appressed but not terminally recurvate or hooked; the lower or inferior pair more removed, terminally recurved below, sharp claw-shaped, slightly divergent, directed inferiorly; anterior to the latter on ventral surface there is a pair of small tubercles. Ten pairs of stigmata or spiracles, as follows: Prothoracic spiracle on side at anterior margin of prothorax; mesothoracic spiracle on anterior border of wing bases; metathoracic spiracle in the anterior lateral angle of dorsum of scutellar segment; and an abdominal spiracle in the anterior lateral corner of dorsum of each of the abdominal segments $I$ to 6 , the 7 th segment having a small median lateral one higher up on side of dorsum; the spiracles (except the mesothoracic) appear as a corneous circle marked by radiating lines within, those on the 7 th segment showing this structure less distinctly, while the mesothoracic spiracle is indistinct and does not usually reveal this structure at all.

Length, $8.5 \mathrm{~mm}$. (including cephalic horns); width of basal abdominal segments, $2.25 \mathrm{~mm}$.; length of long filament-like hairs of $3^{\mathrm{d}}$ to $5^{\text {th }}$ segments about $3 \mathrm{~mm}$., those of Ist and $2 \mathrm{~d}$ segments over $4 \mathrm{~mm}$.

\title{
THE PRIMITIVE NUMBER OF MALPIGHIAN VESSELS IN INSECTS.-I.
}

\author{
BY WilliaM MORTON WHEELER, PH.D., CHICAGO, ILl.
}

Since the days of Schwammerdam anatomists have most naturally evinced far greater interest in the physiology than in the morphology of the Malpighian vessels. Hence we are in possession of a much larger body of facts bearing on the function than on the phylogenetic history of these interesting organs. Their possible relations on the one hand to the tracheæ, which have a somewhat similar orgin, and on the other to vermian nephridia, which have a similar function, are still shrouded in the deepest obscurity. Before these fundamental questions can be answered satisfactorily, it will be necessary, I believe, to come to some definite conclusion in regard to several minor questions. Foremost among these is the question as to the primitive number and arrangement of the organs under consideration.

No fact in insect development is better authenicated than the derivation of the Malpighian vessels. It was Bütschli* who in 1870 first showed that in the bee the paired excretory organs arise as hollow diverticula of the hindgut which itself arises as a more extensive invagination of the ectoderm at the caudal end of the embryo. All succeeding writers have confirmed this observation.

It is worthy of note that there is extensive variation in the time at which the vessels make their appearance in

\footnotetext{
* Zur entwicklungsgeschichte der biene. Zeitschr. f. wiss. zool. 20 . bd. 1870 , p. $54 \mathrm{r}$.
} 

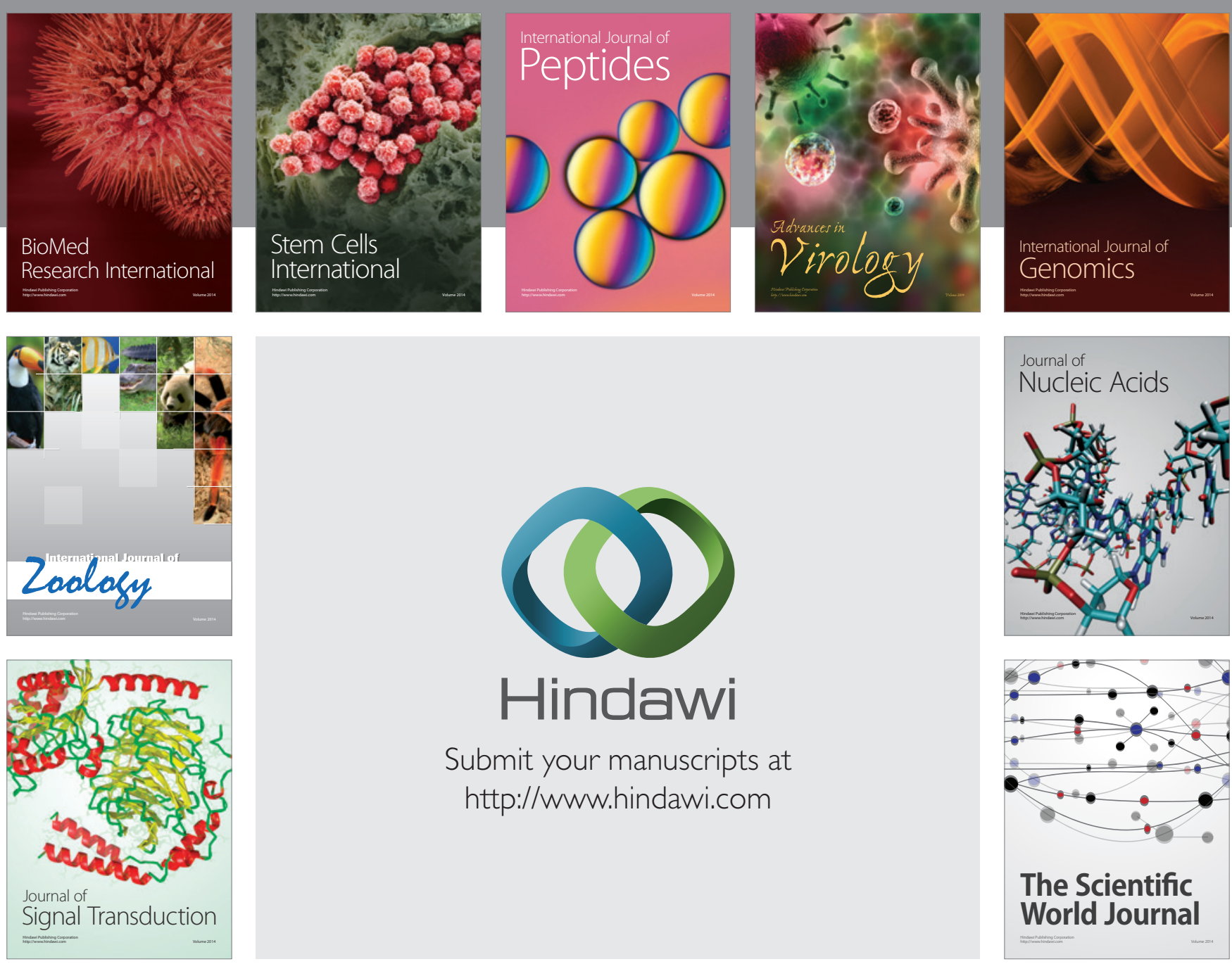

Submit your manuscripts at

http://www.hindawi.com
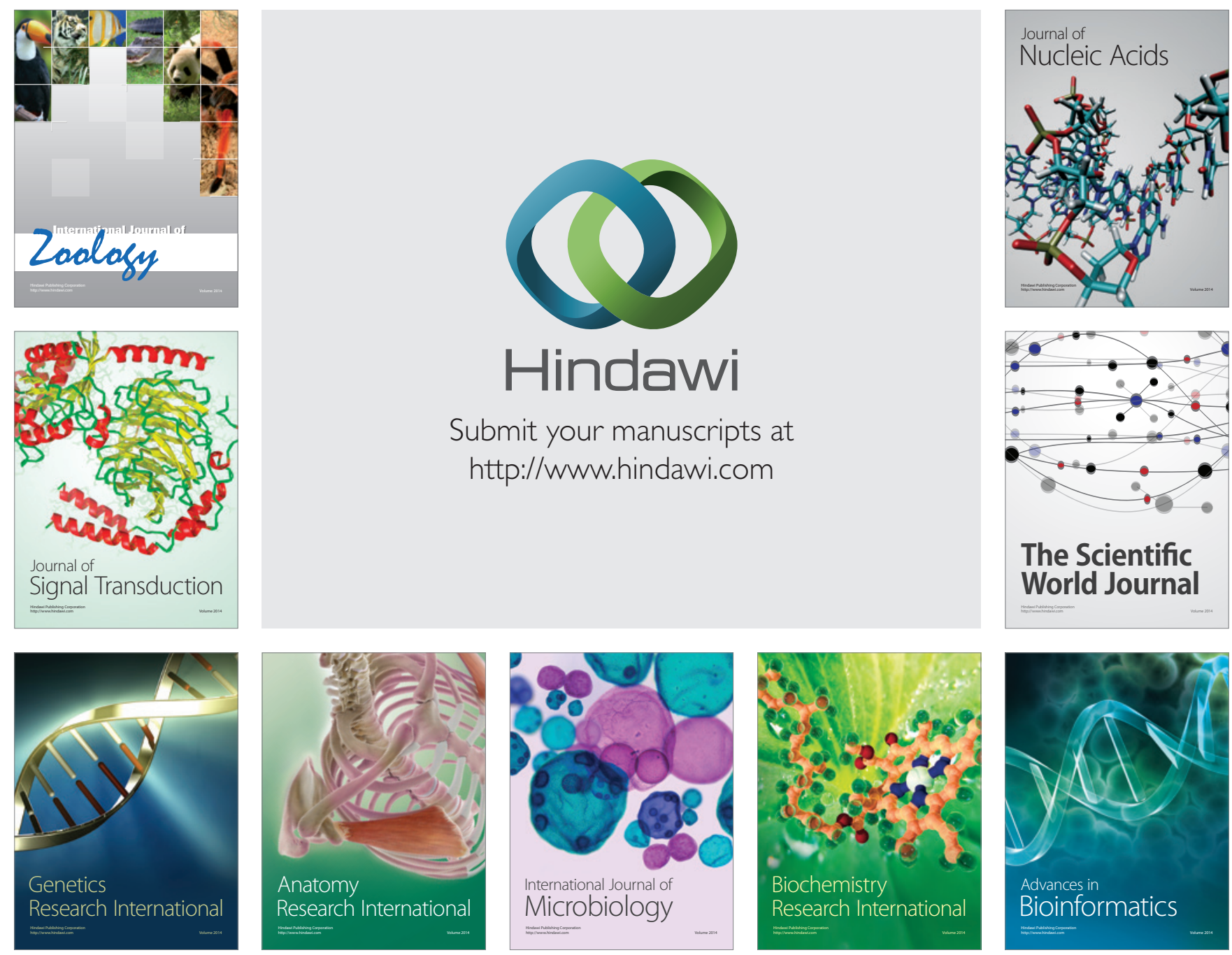

The Scientific World Journal
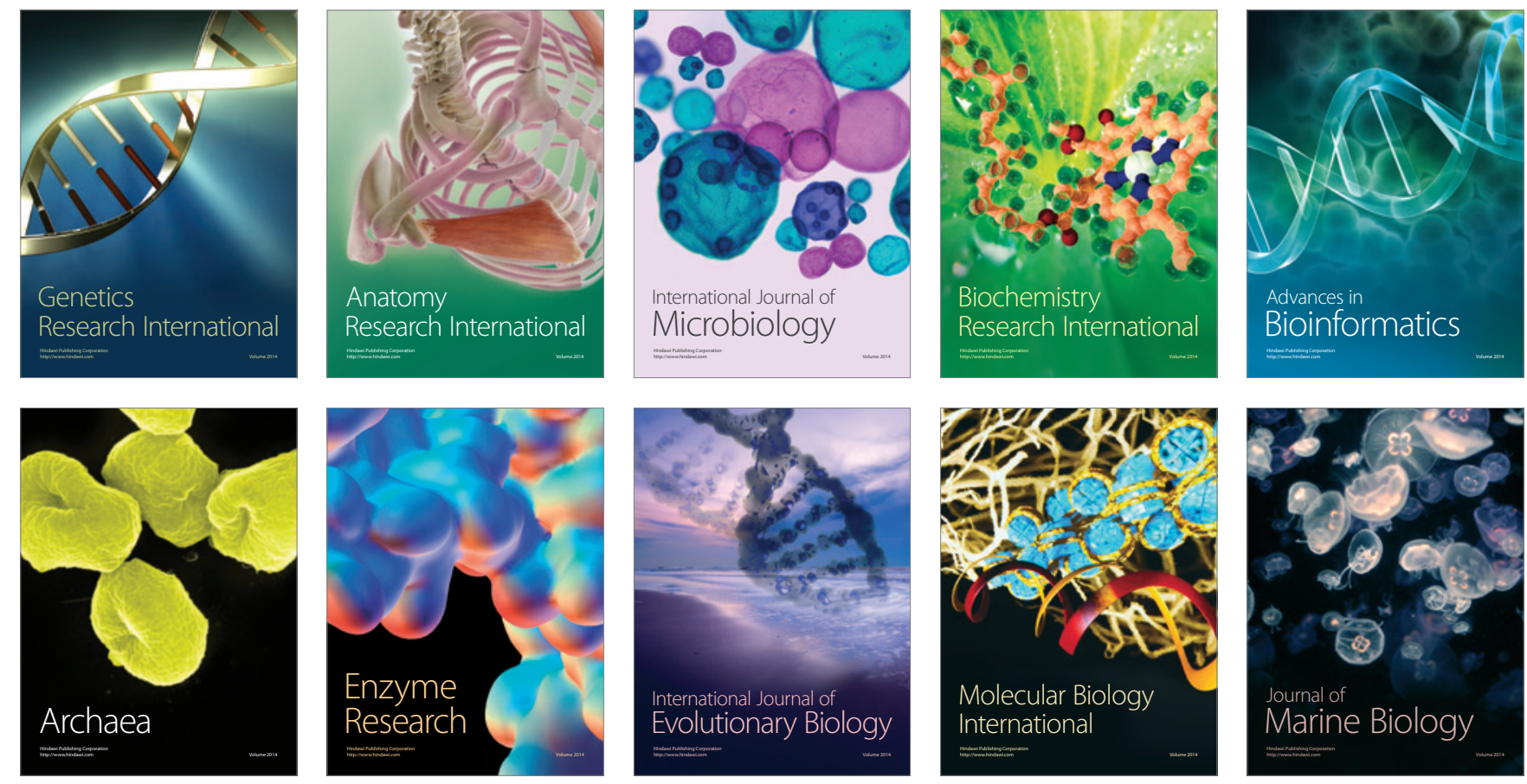